\title{
Historia y funcionamiento de los sistemas de ventilación en túneles de carretera
}

\author{
History and performance of ventilation systems in road tunnels
}

Fecha de envío: 4 de febrero 2021

Fecha de aceptación: 11 de mayo 2021

\section{Alberto Abella ${ }^{1}$, Ignacio García-Arango ${ }^{2}$ y Fernando Hacar ${ }^{3}$ \\ ${ }^{1}$ Vital Aza Álvarez-Buylla 5, $5^{\circ}$ Iz., 33600 Mieres, Principado de Asturias, España, aabella@asturtunel.com \\ ${ }^{2}$ Calvo Sotelo 12, 3 A, 33007 Oviedo, Principado de Asturias, España, igarango42@gmail.com \\ ${ }^{3}$ Avenida de Castilla y León 37, 2 A, 28702 San Sebastián de los Reyes, Madrid, España, fhacar@gmail.com}

Se realiza una exposición de la historia de la ventilación de túneles carreteros y ferroviarios, contemplando algunos túneles notables muy conocidos como: Canal de la Mancha, San Gotardo, puente ferroviario Britannia, el Chorro, Severn, Mersey, Blackwall, Holland, Queensway y Karawanken; importantes en cuanto a la ventilación se refiere. Tras una exposición de los distintos sistemas empleados en la ventilación de túneles de carretera, se continúa por el estudio de cómo las condiciones atmosféricas pueden obligar a una ventilación suplementaria para poder controlar el movimiento del aire en túneles, especialmente en los túneles largos.

Palabras clave: carretera, túnel, ventilación, condiciones atmosféricas
A synthesis of the history of road and railway tunnel ventilation is described, contemplating some notable tunnels such as the well-known Channel Tunnel, St. Gotthard, Britannia railway bridge, the Chorro, Severn, Mersey, Blackwall, Holland, Queensway and Karawanken; important as far as ventilation is concerned. After a presentation of the different systems used in the ventilation of road tunnels, we continue with the study of how atmospheric conditions can force supplementary ventilation to control the movement of air in tunnels, especially in long tunnels.

Keywords: road, tunnel, ventilation, atmospheric conditions

\section{Introducción histórica}

Los primeros túneles destinados al paso de peatones y carruajes con tracción animal no precisaban ventilación mecánica pues con la ventilación natural solía ser suficiente. En algunos más largos se emplearon pozos para la ventilación, y en otros se hacía uso de pozos que habían sido utilizados para la construcción. Si esos túneles discurrían bajo montañas de cierta altura o bajo ríos el problema resultaba más complejo pues esos pozos eran difíciles de realizar.

Los romanos ya empleaban en los tramos subterráneos de sus acueductos los pozos putei o pozos verticales y los cuniculi o pozos inclinados o de acceso para captar las aguas, "hoyas" o pozos para atacar la excavación desde varios frentes, para sacar escombros, para el control topográfico, para el mantenimiento, los spiramina o pozos para la ventilación. Si ésta era insuficiente agitaban mantas en la base del pozo para forzar la ventilación. Algunos de ellos alcanzaron profundidades de hasta $122 \mathrm{~m}$.

Los motores de combustión de los vehículos iban a obligar a importantes cambios en la ventilación de los túneles. Cuando las máquinas de vapor arrastraban los vagones los pasajeros lograban sobrevivir a la experiencia de atravesar un túnel, sufriendo las asfixias correspondientes (González y Hacar, 2015). Pero el monóxido de carbono y algunos otros gases tóxicos emitidos por los nuevos motores ya no permitía garantizar esa supervivencia y la ventilación se volvió imprescindible.

Seguidamente apuntamos ejemplos históricos de túneles desde el punto de vista de la ventilación. Es importante indicar que los túneles que se citan tienen ya muchos 
años y han sido reformados, no ocupándonos de dichas reformas (a excepción del túnel de Karawanken), pues nuestra intención es introducirnos en los orígenes de la ventilación de túneles.

\section{Túnel del Canal de la Mancha (1802)}

La Figura 1 de 1802 reproduce la idea del ingeniero Albert Mathieu-Favier para el túnel del Canal de La Mancha entre Francia y el Reino Unido (Channel Tunnel o Le Tunnel Sous la Manche), diseñado para uso de vehículos de tracción animal.

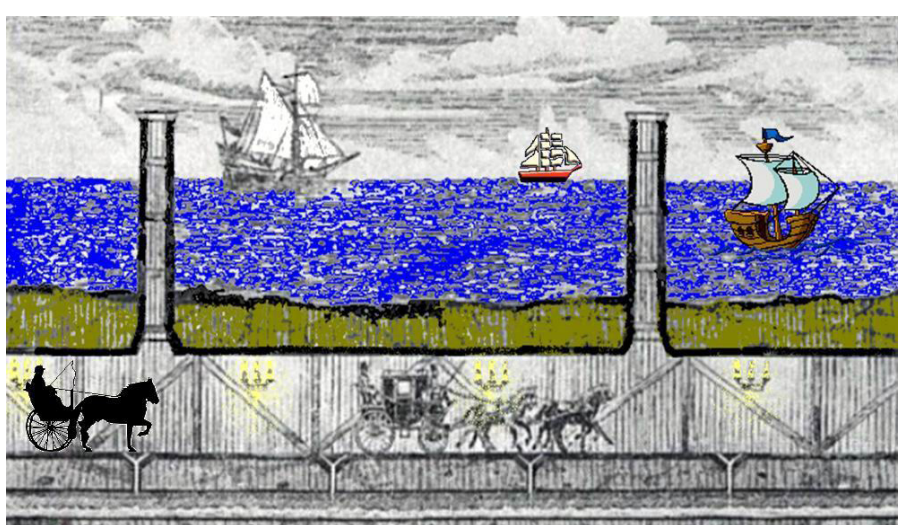

Figura 1: Esquema del túnel del Canal de La Mancha (FranciaInglaterra) propuesto en 1802 por el ingeniero francés Albert Mathieu-Favier

La idea consistía en la ejecución de dos tubos superpuestos, empleando el superior para el servicio postal (en diligencias) entre los dos países y el inferior para drenar las aguas filtradas que serían evacuadas por gravedad hacia ambas bocas. El alumbrado se preveía mediante lámparas de aceite. El proyecto también incluía enormes chimeneas de ventilación que salían al mar. Se contemplaba la construcción de una isla artificial aproximadamente en el centro del túnel, a medio camino entre Dover y Calais, en el banco de arena de Varnes. En ella los usuarios podrían salir a la superficie donde se instalaría una casa de postas para descansar, respirar aire fresco y cambiar de monturas. El cruce del Canal se estimó en alrededor de 5 h 30 min. Este proyecto permaneció expuesto varios años en las vitrinas del Palacio de Luxemburgo y en la Escuela de Minas de París (Jevenois, 1927).

\section{Túnel ferroviario de San Gotardo (1882)}

Tiene la historia de la tracción a vapor interesantes aspectos relacionados con la ventilación de los humos y hollín producidos por las locomotoras. La media hora que se empleaban en 1896 en la travesía de $15 \mathrm{~km}$ por el túnel ferroviario de San Gotardo en Suiza, construido por Louis Favre, era un suplicio, una prueba de supervivencia para los muy atrevidos viajeros (Figura 2).

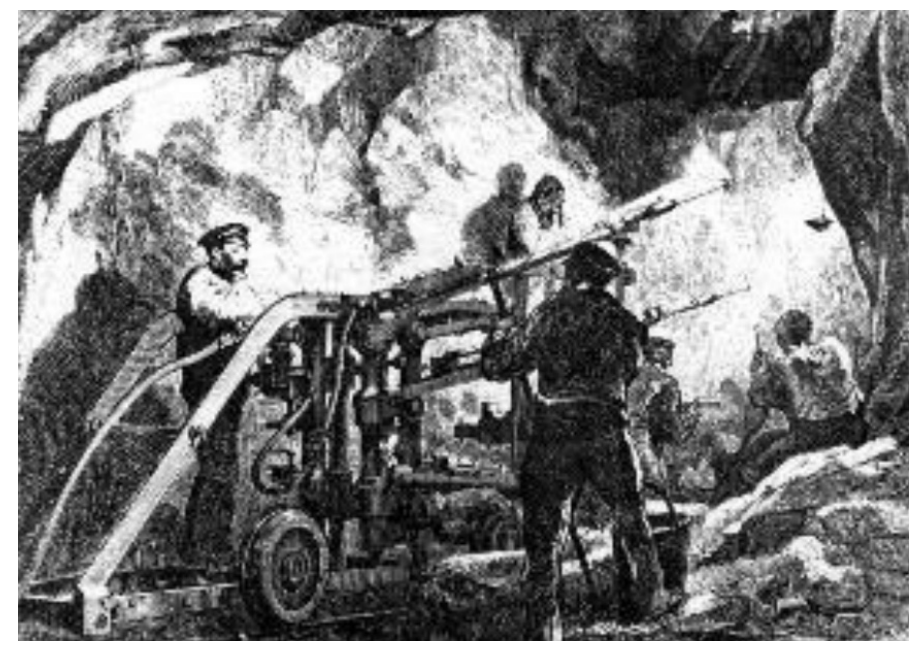

Figura 2: Construcción del túnel ferroviario de San Gotardo en los Alpes Suizos, trabajos de perforación en el frente de Airolo (Sandström, 1963)

\section{Puente ferroviario Britannia (1850)}

No era exactamente un túnel, pero al ser un cajón cerrado, la travesía por los $460 \mathrm{~m}$ del puente ferroviario Britannia en el estrecho de Menai (Gales, Gran Bretaña) era igualmente una aventura (Figura 3). El puente construido para Chester \& Holyhead Railway, siendo el Ingeniero Jefe Robert Stephenson, fue inaugurado en 1850. Lo formaban dos vigas cajón construidas con chapas de hierro forjado roblonado por cuyo interior circulaban los trenes. Las vigas eran de $4.5 \mathrm{~m}$ de ancho, entre 7 y $9.1 \mathrm{~m}$ de alto y para facilitar el mantenimiento las dos vigas estaban separadas entre sí $3.7 \mathrm{~m}$. Para proteger el hierro del clima, cubriendo ambos tubos, se construyó un techo continuo de madera de $12 \mathrm{~m}$ de anchura, arqueado, cubierto con arpillera alquitranada. Un incendio (al parecer originado por unos niños que jugaban con antorchas en el interior del puente) el 23 de mayo de 1970 destruyó la techumbre de madera alquitranada debilitando las vigas cajón y obligando a la reconstrucción total del puente. Las vigas cajón de hierro forjado de Stephenson se reemplazaron por arcos de acero que soportan un tablero con dos niveles: para el ferrocarril en el nivel inferior y para carretera el superior. Se inauguró en 1972. 
Los viajeros que lo cruzaban en 1902 sufrían calor, toses y agobios debido a los gases y hollín que soltaban las locomotoras de vapor que tiraban de los vagones:

Está uno atento mirando cuando de pronto escucha un estruendo sordo que aumenta gradualmente hasta que el tren, con un infernal estampido metálico y la reverberación de un millón de ecos, sale como una exhalación, arrastrando tras de si una vaharada de aire que hiede a la atmósfera saturada de hollín que, tras cincuenta años de uso, nada logra extraer de los tubos, y que se parece abominablemente al olor de una chimenea doméstica sucia (Anónimo, 1849).

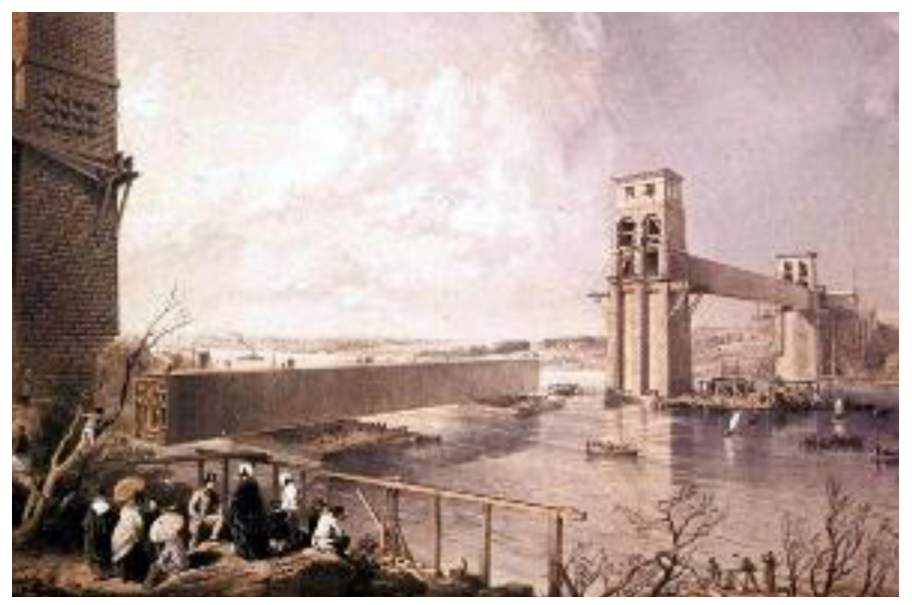

Figura 3: Puente Britannia, estrecho de Menai, Gales, Gran Bretaña (ice.org.uk)

\section{Túnel ferroviario del Chorro (1860)}

Como curiosidad señalamos el caso en España del único túnel ferroviario que tuvo ventilación artificial. Se trata del túnel $\mathrm{n}^{\circ}$ 12, Túnel del Chorro (también se le denomina del Viaducto) de la Compañía del Ferrocarril de Córdoba a Málaga, línea ferroviaria construida entre 1860 y 1865, habiendo en la estación inmediata de El Chorro, situada entre dos túneles en los extremadamente abruptos desfiladeros de los Gaitanes, una caseta de transformación con un ventilador y una tubería de aire que se desmontó el 1 de diciembre de 1969 (Fonseca, 1987).

\section{Túnel ferroviario de Severn (1886)}

El túnel, también ferroviario, de Severn, entre Gloucestershire (Inglaterra) y Monmouthshire (Gales), en el estuario del río Severn (Reino Unido), de $7 \mathrm{~km}$ de longitud (3.6 km están bajo el río Severn) (Figura 4). Construido por Great Western Railway GWR, durante su construcción, entre 1873 y 1886, se dispuso de una instalación de ventilación mediante ventiladores que aportaban aire fresco desde el pozo del banco de arena de Sudbrook en el lado Gales. Actualmente, en la parte alta de ese pozo, un ventilador de $8 \mathrm{~m}$ de diámetro impulsa aire fresco desde el exterior hacia el interior del túnel.

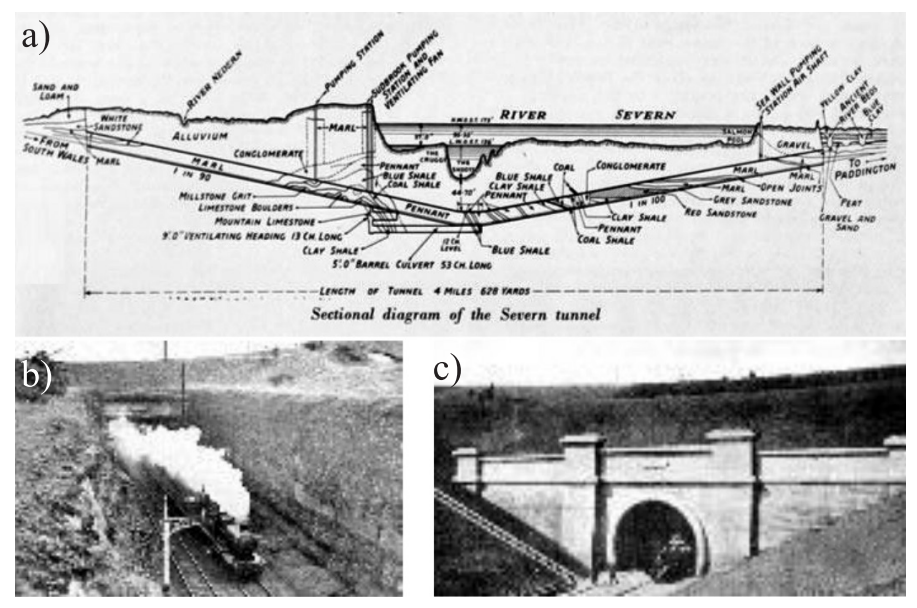

Figura 4: a) Perfil longitudinal del túnel ferroviario bajo el río Severn (Inglaterra-Gales, Reino Unido) (The Engineer, 1879), b) portal lado Gales y c) portal lado Inglaterra

\section{Túnel ferroviario de Mersey (1886)}

Para resolver la barrera que separaba las dos orillas del río Mersey, la ciudad de Liverpool y la península de Wirral, se construyeron varios túneles. En 1886, el túnel ferroviario de Mersey fue el primer túnel ventilado artificialmente (Figura 5). Se excavaron un total de 3 túneles: el del propio túnel para doble vía (de $1.2 \mathrm{~km}$ ), el de drenaje (de $1.6 \mathrm{~km}$ ) y el de ventilación (de $2.1 \mathrm{~km}$ ), estos dos últimos de $2.18 \mathrm{~m}$ de diámetro. La construcción comenzó por la excavación de 2 pozos - uno a cada lado del río - para el bombeo de las aguas de filtración. El pozo lado Liverpool de $4.6 \mathrm{~m}$ de diámetro y el de Birkenhead de $5.3 \mathrm{~m}$. Ambos con una profundidad de $52 \mathrm{~m}$. Fue instalado un ventilador en cada pozo (de 12.2 m y $9.1 \mathrm{~m}$ de diámetro) para la renovación del aire del túnel cada $7 \mathrm{~min}$.

Si bien se había previsto en este túnel ferroviario de doble vía un sistema de ventilación para la renovación del aire, cuando el tráfico ferroviario aumentó, debido a la atmósfera irrespirable que se producía en el túnel al paso de las locomotoras de vapor y que la ventilación no era capaz de resolver, los usuarios optan por el cruce en los muy eficientes - aunque ya rebasando su capacidad de transporte - transbordadores que se empleaban, produciéndose en 1900 la quiebra de la Mersey Railway Company. 
a)

b)
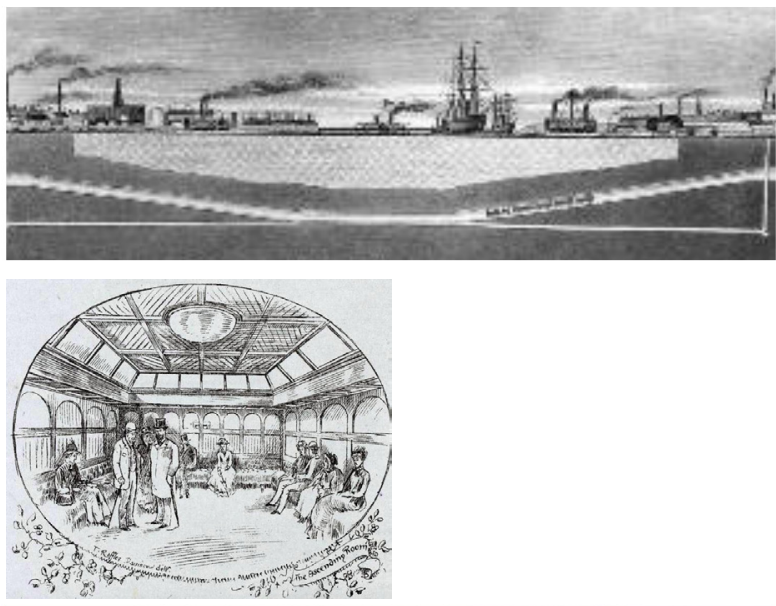

c)

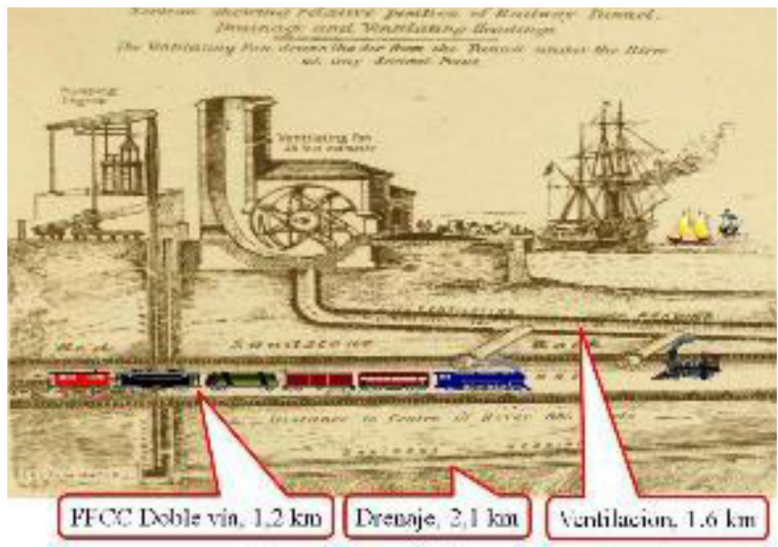

Figura 5: a) Perfil longitudinal del túnel ferroviario de Mersey entre Liverpool y la península de Wirral, b) ascensores hidráulicos con capacidad para 100 personas para acceder desde la superficie a las estaciones de James Street (Liverpool) y de Hamilton Square (Birkenhead) y c) esquema de tres túneles construidos: doble vía para ferrocarril, drenaje y ventilación.

La línea recuperaría su protagonismo tras la electrificación en 1903, electrificación que tardó en llegar a ese túnel, pues veinte años antes la tracción eléctrica ya se empleaba en la C\&SLR, City and South London Railway, inaugurada en 1890. El túnel de Queensway, el primero de los túneles carreteros bajo el mismo río Mersey, fue inaugurado en 1934 y durante 24 años fue el túnel subacuático más largo del mundo. Más tarde, en 1971, se abrió al tráfico el segundo túnel de carretera, el de Kingsway.

\section{Túnel de Blackwall (1897)}

El túnel de Blackwall bajo el río Támesis se construyó entre 1892 y 1897 (Figura 6). Diseñado inicialmente para tráfico peatonal, caballos y vehículos de tracción animal (para tráfico bidireccional), representa un buen ejemplo de un túnel que aún sigue operativo, siendo ahora unidireccional (tras importantes reformas) pues se encuentra duplicado. a)

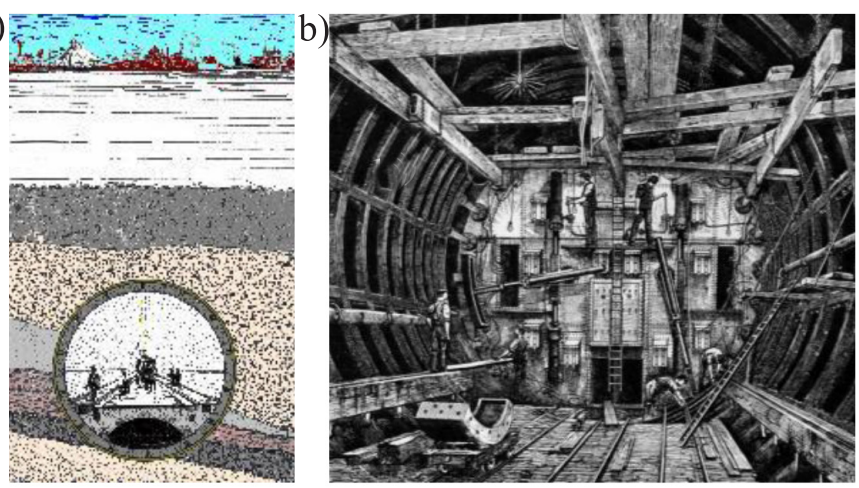

c)

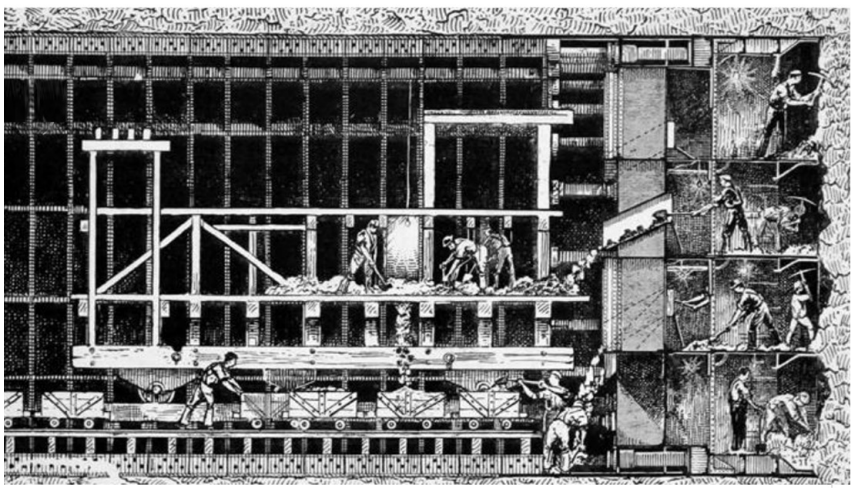

Figura 6: a) Túnel de Blackwall bajo el río Támesis en Londres (Legouëz, 1897), b) y c) escudo presurizado en arcilla (gracesguide.co.uk)

Este túnel es notable, entre otros aspectos, por formar parte importante de la historia de los escudos presurizados (antecesores de las modernas tuneladoras) empleados en la excavación de túneles bajo el agua (Figura 6b,c).

Se construyeron 4 pozos de $17.7 \mathrm{~m}$ de diámetro exterior e interior de $14.6 \mathrm{~m}$, con profundidades entre 23 y 30 $\mathrm{m}$, siendo recta la alineación en planta entre pozos, y cambiando la alineación en cada pozo, evitando con ese trazado la afección a más inmuebles en superficie. Dos de esos pozos disponían de escaleras helicoidales que permitían el acceso peatonal; otro pozo se empleó como edificio administrativo; y el cuarto para ventilación. El túnel cruza bajo el río Támesis, en el este de Londres, conectando Poplar (boca norte) con Greenwich (boca sur). Con una longitud de $1889.73 \mathrm{~m}$ fue el túnel subacuático más largo del mundo. Diámetro exterior $8.2 \mathrm{~m}$, interior de $7.4 \mathrm{~m}$, profundidad $24.4 \mathrm{~m}$, calzada de $4.9 \mathrm{~m}$ y aceras de $0.95 \mathrm{~m}$. Excavado con escudo presurizado, dovelas metálicas forman el revestimiento con anillos de $0.8 \mathrm{~m}$ de longitud (peso total de cada anillo 16.8 t) formado por 14 dovelas más una de cierre. Hacia 1930 el túnel es insuficiente para el tráfico que lo ha de emplear, por lo que 
se decide duplicarlo, comenzándose las obras del nuevo túnel en marzo de 1960 y concluyendo el 2 de agosto de 1967.

\section{Túnel de Holland (1927)}

El primer túnel de carretera ventilado artificialmente con ventilación transversal fue el túnel de Holland, bajo el río Hudson (Figura 7), conectando New York con New Jersey, fue construido entre 1920 y 1927 (Holland, 1921). El túnel lleva el nombre de Holland en memoria del ingeniero a cargo del proyecto Clifford Holland (1883-1924). Formado por dos tubos túneles de $2600 \mathrm{~m}$ y $2550 \mathrm{~m}$ de longitud, con un ancho de calzada $6.0 \mathrm{~m}$ (dos carriles por sentido) y gálibo vertical de $3.8 \mathrm{~m}$.

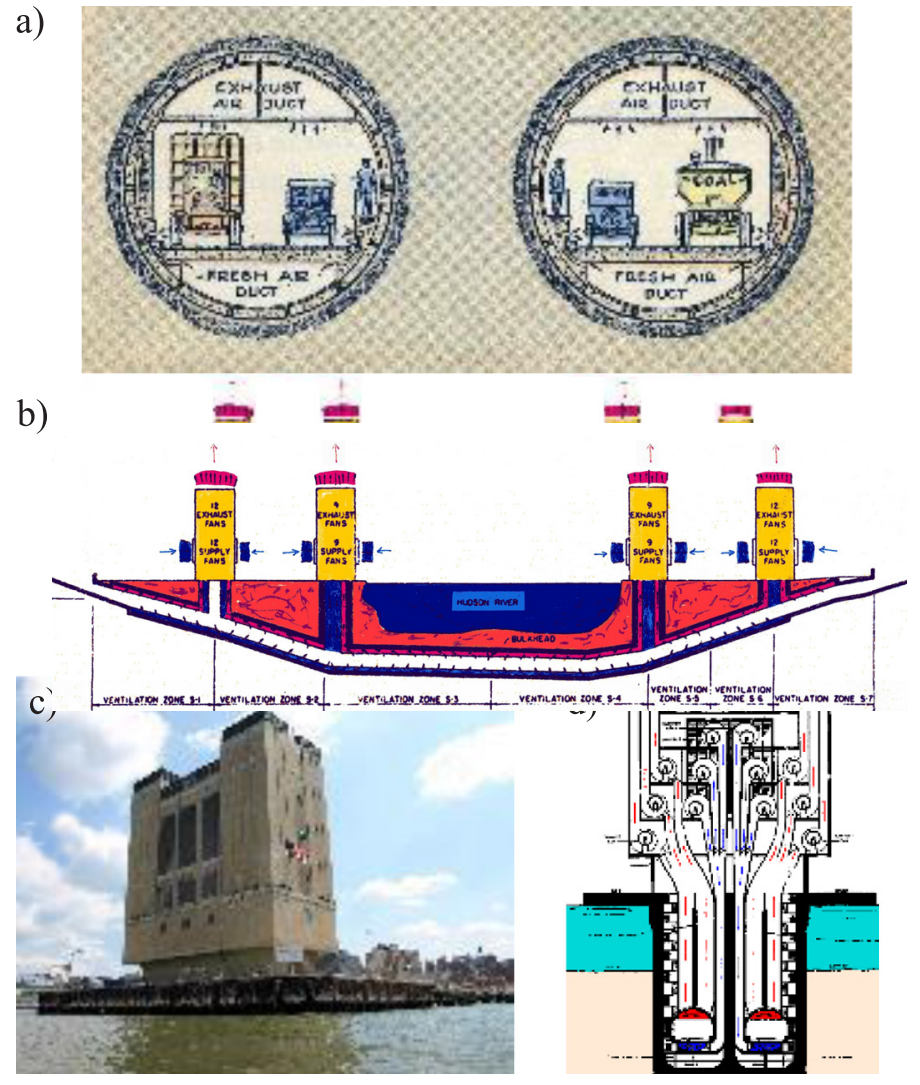

Figura 7: Túnel de Holland bajo el río Hudson entre New York y New Jersey, EEUU: a) esquema de los dos tubos (hobokenmuseum.org), b) diagrama de ventilación (Bendelius, 1982), c) edificio de ventilación y d) esquema de ventilación en una de las torres del río.

Para el diseño del revolucionario sistema de ventilación transversal de este túnel, entre los años 1919 y 1922, el ingeniero Ole Singstad realizó estudios con modelos de túneles a escala real relativos a las emisiones de CO por los vehículos como los efectos que causaban en las personas los ambientes con diferentes concentraciones de dicho gas tóxico (Gray y Hagen, 1931).

Los criterios iniciales sobre ventilación establecían un límite máximo de $\mathrm{CO}$ en el túnel independientemente del tiempo de exposición, y, de esa manera, cuando en 1927 se abrió al tráfico el túnel ese valor máximo en la concentración de $\mathrm{CO}$ se estableció en 400 ppm, si bien las concentraciones medias eran mucho más bajas.

El resultado de esos estudios fue la instalación de un sistema de ventilación transversal, con capacidad de aportar un caudal de aire fresco y aspirar el viciado suficiente para diluir la concentración calculada de 160 ppm, que es la que generaba una emisión de $68 \mathrm{l} / \mathrm{min}$ para el tráfico de diseño a velocidad media de $48.2 \mathrm{~km} / \mathrm{h}$. La sección circular de los túneles permitió emplear el sector circular sobre y bajo el espacio destinado al tráfico como conductos de ventilación.

El túnel sigue operativo. Obviamente se han acometido importantes reformas. No tardaron en bajarse esos límites admisibles de CO. En 1975 se estableció para túneles no urbanos entre 150 y 250 ppm, con un máximo absoluto de 300 ppm en la zona de las bocas de salida y en el caso de ventilación longitudinal. En 1979 se estableció en 150 ppm con un límite absoluto de 250 ppm durante 5 ó 15 min en picos de congestión, por accidentes y en otras situaciones excepcionales así como en las bocas de salida en el caso de ventilación longitudinal.

Los criterios de diseño de la ventilación desde los tiempos del túnel de Holland respondían a la idea de reducir los contaminantes en el aire del túnel hasta límites aceptables. Desde hace algunos años, con la importante reducción de las emisiones de contaminantes emitidos por los vehículos, el criterio que más (no siempre) suele influir en el diseño de la ventilación es el del control de humos en caso de fuego.

\section{Túnel de Queensway (1934)}

También el primer túnel carretero de Mersey, el Queensway (Figura 8), inaugurado 1934, es un magnífico ejemplo del nacimiento de la ingeniería de la ventilación de túneles (Yagües, 2011). Conectando igualmente Liverpool y la Península de Wirral (Birkenhead) reemplazó al tráfico de ferries en el cruce del Mersey. El 16 de diciembre de 1925 comienzan los trabajos en el lado Liverpool, y el 10 de marzo de 1926 lo hacen en el lado Birkenhead. 


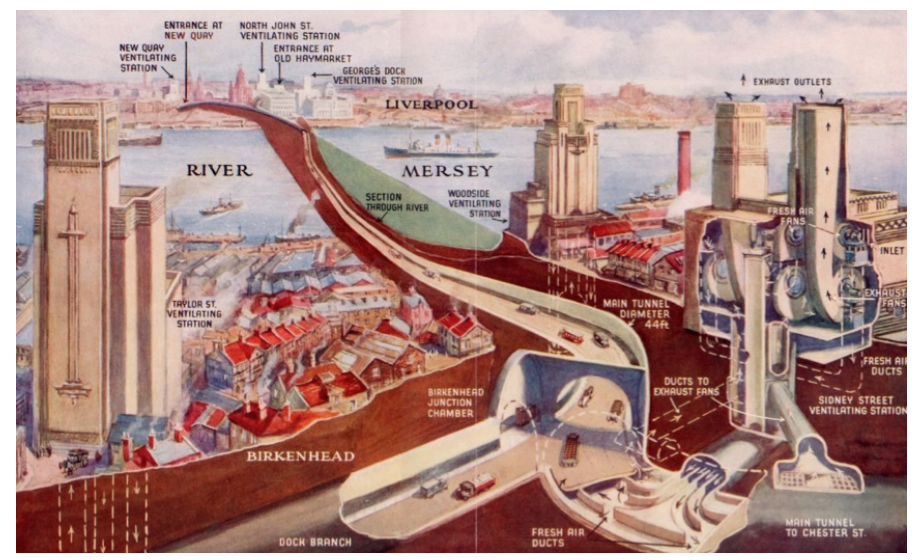

Figura 8: Primer túnel de carretera Queensway bajo Mersey entre Liverpool y la Península de Wirral, Reino Unido, se destacan los edificios de ventilación

Túnel de 3219 m longitud con tráfico bidireccional, 2 carriles en cada sentido, ancho de la calzada $11 \mathrm{~m}$, diámetro del túnel $13.4 \mathrm{~m}$, gálibo vertical de $3.9 \mathrm{~m}$ en los carriles adyacentes a los hastiales y de $4.8 \mathrm{~m}$ en los carriles centrales (los autobuses están obligados a utilizarlo). El punto más bajo del túnel está a $52 \mathrm{~m}$ bajo el río Mersey.

Para la ventilación semitransversal se cuenta con seis estaciones de ventilación extractoras, 3 en cada lado del río Mersey (en el lado Liverpool: muelle George, North John Street y New Quay; en el lado Birkenhead: Woodside Tower, Sydney Street y Taylor Street).

En ambos casos los trabajos se inician con pozos de $61 \mathrm{~m}$ de profundidad y $6.5 \mathrm{~m}$ de diámetro y dos galerías piloto de 4.6 y $3.7 \mathrm{~m}$ de diámetro, correspondiendo a la parte alta y a la baja de la sección del túnel (según el diseño inicial, el túnel dispondría de 4 carriles en el nivel superior, así como permitiría el paso de dos tranvías por la parte inferior), y por ello la sección resultante fue de $13.4 \mathrm{~m}$ de diámetro.

Fue revestido con dovelas de hierro fundido de $183 \mathrm{~cm}$ de longitud, entre $61.0 \mathrm{~cm}$ y $76.2 \mathrm{~cm}$ de ancho y $34.3 \mathrm{~cm}$ de canto, con un peso de cada dovela de $864 \mathrm{~kg}$. Se finalizó el revestimiento construyendo una capa de hormigón cubriendo los huecos vistos de las dovelas, sobre ella otra capa de gunita (con y sin armadura, según los casos, y de espesor entre 6 y $10 \mathrm{~cm}$ ), y un tratamiento superficial estético y para impermeabilización (Marplax).

El túnel fue puesto en servicio el 17 de diciembre de 1933, e inaugurado oficialmente el 18 de julio de 1934. En su momento, y durante 24 años, fue el túnel subacuático más largo del mundo. Este túnel es ligeramente posterior al de Holland y los estudios de ventilación son en parte similarmente complejos y pioneros en la ventilación de túneles de carretera.

Más tarde, las necesidades del tráfico generaron la construcción del segundo túnel carretero bajo el Mersey, el llamado túnel de Kingsway, comenzado en 1966 y abierto al tráfico en 1971. Se trata de dos túneles, gemelos, con sección circular de $9.2 \mathrm{~m}$ diámetro, cada túnel con 2 carriles de $4.0 \mathrm{~m}$ y de $2.2 \mathrm{~km}$ de longitud. Dispone de una galería de emergencia entre ambos túneles así como de escaleras para evacuación en cada uno de los dos pozos de ventilación. Las aceras son elevadas respecto a la calzada. Los vehículos pesados están autorizados a pasar por este túnel debido a las importantes limitaciones del túnel de Queensway (carriles de $3.00 \mathrm{~m}$ ).

\section{Túnel de Karawanken (1991)}

El túnel transalpino de Karawanken, construido entre 1987 y 1991 entre Austria y Slovenia, tiene $7.9 \mathrm{~km}$ de longitud ( $8 \mathrm{~km}$ incluyendo portales, $4.4 \mathrm{~km}$ en Austria, lado norte y $3.5 \mathrm{~km}$ en Slovenia, lado sur), es bidireccional, 2 carriles y una sección libre de $48.8 \mathrm{~m}^{2}$ (Figura 9). Conecta Villach en Austria (autopista A11) con Ljubljana en Slovenia (carretera A2). El portal norte tiene una altitud de 655.3 msnm y el portal sur $620.7 \mathrm{msnm}$ con pendientes de norte a sur de $+0.50 \%$ (en $3880 \mathrm{~m}$ ) y $-1.35 \%$ (en $3984 \mathrm{~m}$ ).

En 1978 la ventilación fue estudiada con el sistema semitransversal/transversal según el criterio $\mathrm{CO}$ con 2 pozos (de 200 y $565 \mathrm{~m}$ ), con capacidad para insuflar un caudal de aire fresco de $100 \mathrm{~m}^{3} /(\mathrm{s} \cdot \mathrm{km})$ y extraer $80 \mathrm{~m}^{3} /$ $(\mathrm{s} \cdot \mathrm{km})$, necesitándose una potencia de $3460 \mathrm{~kW}$ para mover un total de $1415 \mathrm{~m}^{3} / \mathrm{s}$.

Como las obras comenzaron tiempo después del diseño original, y en ese lapso de tiempo los avances en la tecnología de la ventilación fueron considerables, se procedió a un rediseño de la misma. Los datos de tráfico de 1990 indicaban que el porcentaje de vehículos pesados diesel había aumentado respecto a los que habían sido considerados en el diseño original (pasando de 9.5 a 44\%), así como los límites admisibles de CO habían disminuido (pasando de 226 a 150 ppm). De esa manera se instaló un sistema de ventilación semitransversal/transversal ( $\sin$ 
pozos, con falso techo con conductos para aire fresco y aire viciado de $9 \mathrm{~m}^{2}$ cada uno) excepto en los $1200 \mathrm{~m}$ centrales en los que únicamente se instalaría un sistema longitudinal con jet-fans ( $\sin$ falso techo).

Se diseñó la ventilación para una aportación de aire fresco de $80 \mathrm{~m}^{3} /(\mathrm{s} \cdot \mathrm{km})$, esto es, $20 \%$ menos que el calculado en 1978. Sería el túnel más largo del mundo sin pozos de ventilación.

La reforma del sistema de ventilación resultó necesaria para de ese modo poder cumplir con la normativa vigente (Directiva 2004/54/CE; RVS 09.02.31, 2008), pues el túnel no disponía de un sistema de extracción de humos en su parte central (1200 m), ni la capacidad de extracción masiva de humos en caso de incendio cumple con los estándares de un mínimo de $120 \mathrm{~m}^{3} / \mathrm{s}$ en una longitud de $150 \mathrm{~m}$.

De esta forma, los diseños para la reforma del túnel (IMD de $14000 \mathrm{veh} /$ día, 15\% de pesados) incluyen la ejecución del falso techo en los $1200 \mathrm{~m}$ centrales del túnel y la modificación de la ventilación (fuego de diseño de 50 MW) de manera tal que la capacidad de extracción masiva de humos se eleva a 200 y $280 \mathrm{~m}^{3} / \mathrm{s}$ (según el sistema de

a)

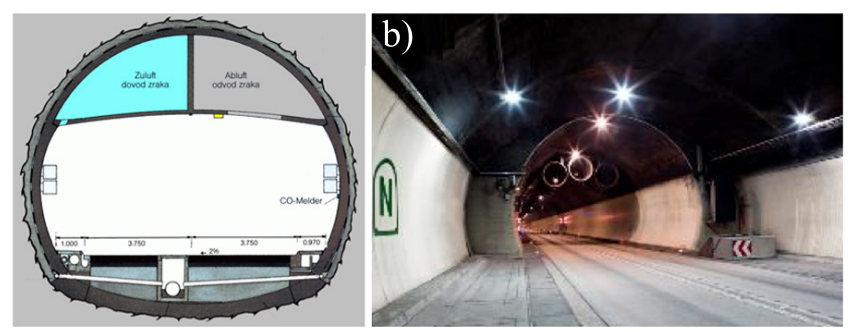

c)

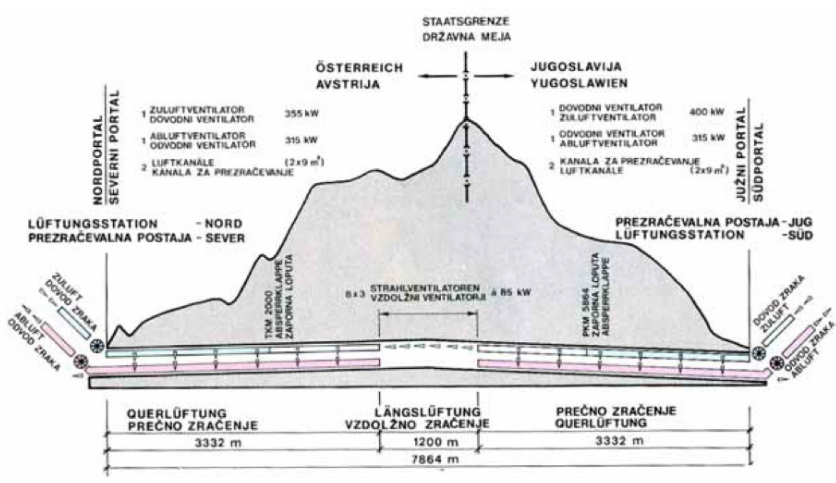

Figura 9: Túnel de Karawanken entre Eslovenia y Austria, a) sección transversal, b) vista interior en la parte del túnel sin falso techo, estado anterior a la reforma (Asfinag Bmg, 2014) y c) perfil longitudinal esquemático de la ventilación, en $1200 \mathrm{~m}$ de la parte central del túnel no existen conductos de ventilación para extracción de humos (Brandt y Cufer, 2006) operación) en $150 \mathrm{~m}$, superando así el requerimiento de que el túnel sea capaz de extraer un mínimo de $120 \mathrm{~m}^{3} / \mathrm{s}$ en esa longitud.

\section{Sistemas de ventilación en túneles de carretera}

\section{Sistemas de ventilación más frecuentes}

La ventilación es de gran importancia en la explotación de un túnel, pudiendo llegar a ser determinante en caso de accidente con fuego (Alarcón, 2011). Los objetivos que se pretenden con la ventilación son:

a) Ventilación ordinaria:

- Mantener en todo momento la calidad del aire en el túnel adecuada para que la toxicidad no alcance los límites prefijados.

- Garantizar que la visibilidad sea segura para la conducción.

b) Ventilación de emergencia:

- Reducir al máximo la gravedad en caso de emergencia.

c) Ventilación por condiciones de confort.

Dependiendo de factores como la longitud del túnel, la intensidad de tráfico y la inclinación, en túneles de carretera normalmente se emplean los sistemas de ventilación mostrados en la Figura 10.

\section{Ventilación natural}

Es un sistema de ventilación natural, no mecánica, la ventilación se produce principalmente por diferencia de presión entre las bocas y/o efecto pistón generado por el desplazamiento del aire generado por el tráfico en movimiento, efectos que sumados (no siempre suman en el mismo sentido) pueden llegar a crear una corriente natural suficiente de aire en el túnel para lograr su ventilación. Suele emplearse en túneles no urbanos, muy cortos (no superiores a 200 ó 300 m) y con poco tráfico.

\section{Ventilación natural con pozo}

Este sistema es similar al natural complementado con el efecto chimenea generado por el pozo de ventilación, pozo por donde sale al exterior parte o todo el aire contaminado del túnel. Como sucede con el sistema de ventilación natural, según sean las condiciones atmosféricas (las que 


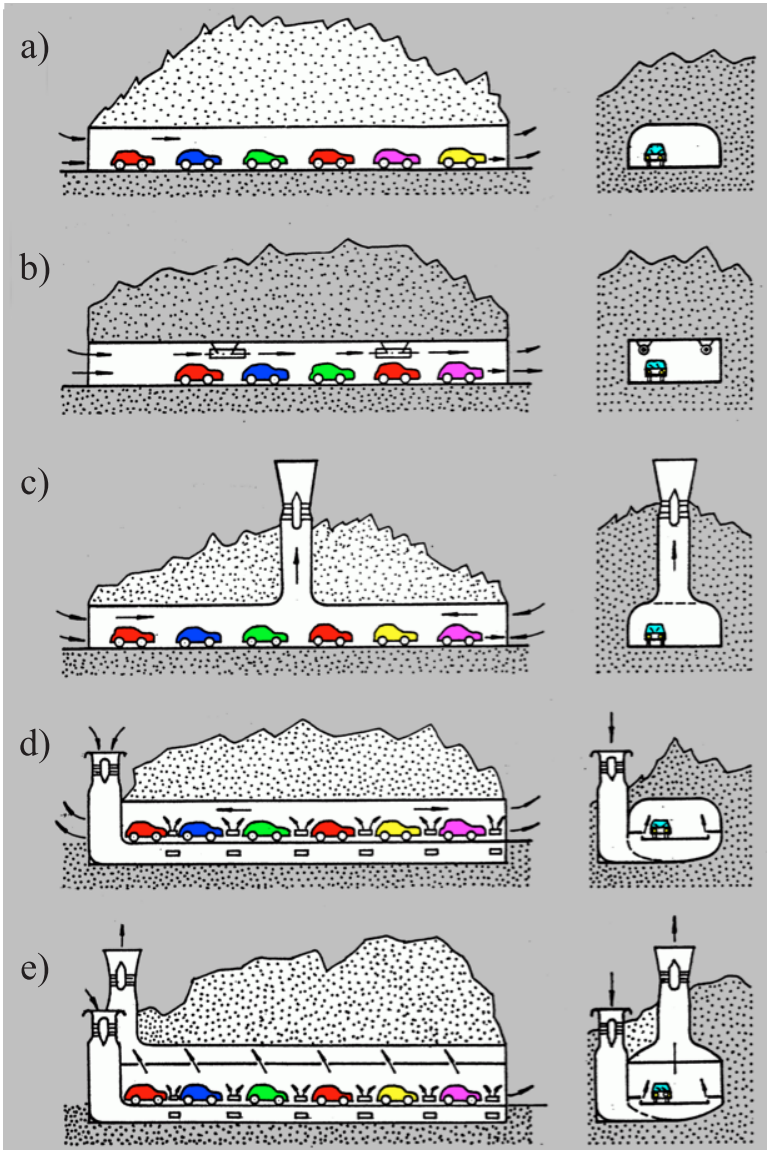

Figura 10: Esquemas de sistemas de ventilación empleados en túneles carreteros: a) Ventilación natural, b) longitudinal con ventiladores de chorro, c) longitudinal con pozos, d) semitransversal con inyección de aire fresco y e) transversal pura

pueden variar incluso varias veces a lo largo del día) el sistema puede funcionar de forma imprevista y no tener posibilidad de controlarlo. Este sistema fue empleado en ocasiones (también en túneles ferroviarios) haciendo uso de los pozos que se habían utilizado para la construcción del túnel. Actualmente no se emplea.

\section{Ventiladores longitudinales de chorro}

En este tipo de ventilación se instalan ventiladores de chorro (aceleradores o jet-fans) a lo largo del túnel (Figura 11) los cuales empujan el aire creando una corriente longitudinal de aire en el túnel. Este tipo de ventilación está indicada para túneles unidireccionales incluso largos. Su gran ventaja es su relativo reducido coste, tanto de instalación como de mantenimiento y explotación. La estrategia más frecuente de ventilación en caso de incendio es la de impulsar los humos hacia la boca de salida, evitando (o limitando) el retroceso de los humos (backlayering) en la zona anterior al fuego en la que presumiblemente se ha producido la retención de vehículos (Figura 12).

En túneles bidireccionales (o aquellos que ocasionalmente puedan funcionar como bidireccionales) es importante que los ventiladores sean reversibles para así permitir el control de humos en caso de fuego.

a)

b)
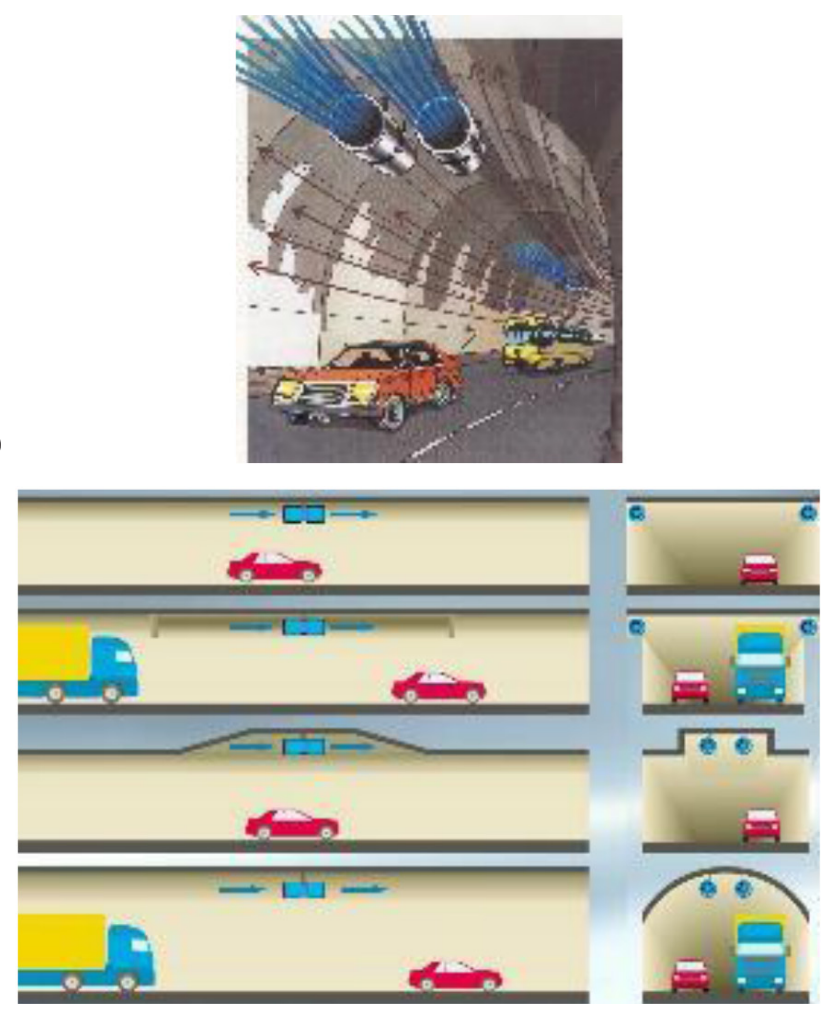

Figura 11: a) Ventiladores de chorro (voith.com) y b) ventilación longitudinal con jet-fans (howden.com)

\section{Ventilación longitudinal con pozos}

Este sistema de ventilación posibilita parcialmente el control del aire viciado en el sentido previsto. Es frecuente diseñar los pozos de forma tal que tanto insuflen aire fresco como extraigan el viciado. En caso de fuego el sistema podría presentar problemas para controlar el desplazamiento de humos.

\section{Ventiladores longitudinales de chorro y pozos con ventiladores axiales}

Este sistema de ventilación presenta la ventaja de que el pozo de extracción permite sectorizar el túnel, posibilitando mayores longitudes, además de poder controlar el movimiento de humos en caso de fuego (Figura 13). 
a)

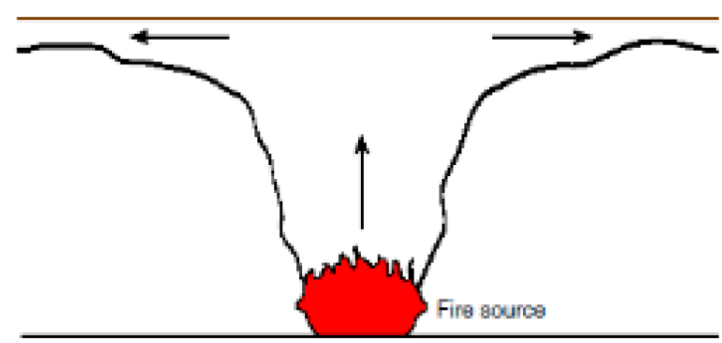

b)

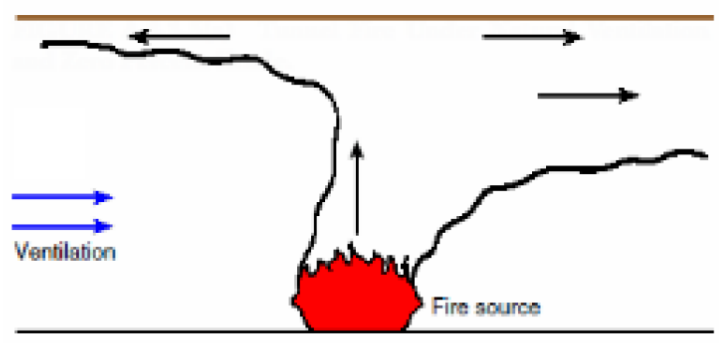

c)

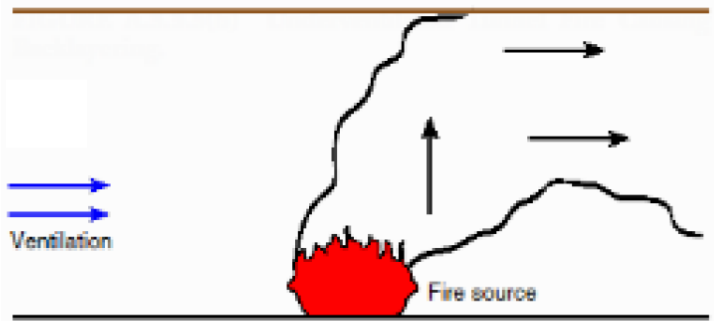

Figura 12: a) Túnel con ventilación natural y $0.0 \%$ de inclinación, b) ventilación insuficiente con retroceso de los humos (backlayering) y c) ventilación suficiente

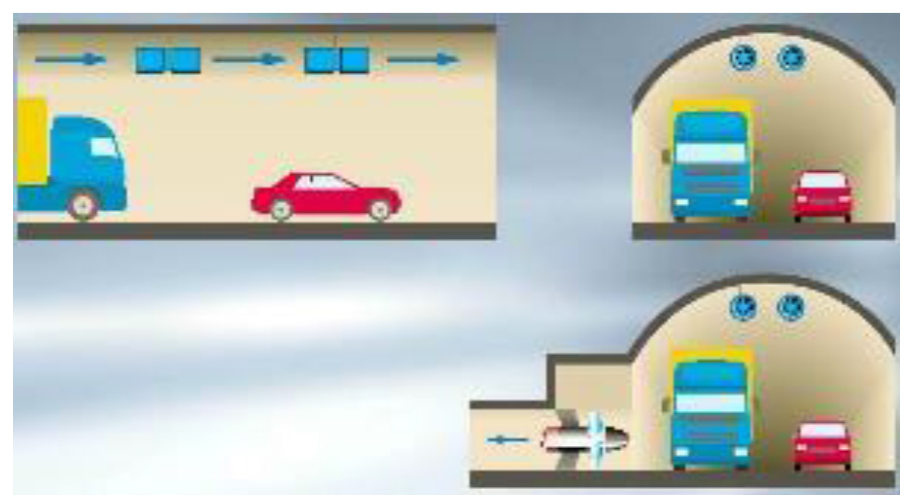

Figura 13: Ventilación longitudinal con jet-fans y suplementario sistema de extracción con ventiladores axiales en el centro del túnel

Ventilación semitransversal con inyección de aire fresco

Este sistema de ventilación aporta en cada zona del túnel el caudal de aire fresco necesario para diluir los contaminantes que se generan en esa zona. El aire fresco se inyecta a través de unas aberturas (trampillas) distribuidas a lo largo del túnel, aberturas que reciben el aire procedente de un conducto (o más de uno) construido en el túnel en el falso techo, bajo la calzada o en los hastiales. El aire viciado sale por las bocas. Este sistema no resuelve la extracción de aire viciado ni la de humos en caso de incendio.

\section{Ventilación semitransversal con inyección y extracción de aire}

También denominado sistema de ventilación semitransversal reversible (Figura 14). Para poder evacuar los humos en caso de incendio la ventilación se diseña tal que pueda invertirse (total o parcialmente) el sentido del aire en los conductos de ventilación, pasando de inyectar aire a aspirarlo a lo largo del túnel (o bien en zonas localizadas). Para la extracción masiva de humos en caso de incendio se instalan trampillas de gran tamaño (exutorios o dampers) que se pueden abrir o cerrar según las necesidades.

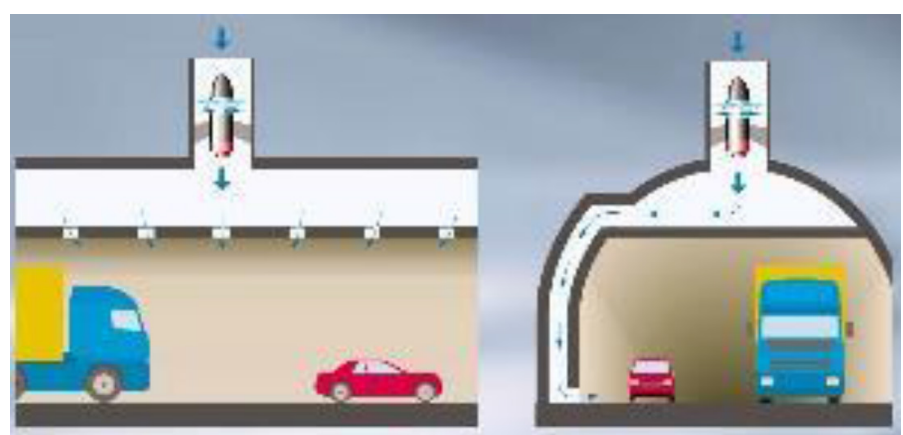

Figura 14: Ventilación semitransversal

\section{Ventilación transversal pura}

En este sistema la ventilación ha de diseñarse de forma tal que cada sección del túnel reciba exactamente la cantidad de aire fresco necesaria para diluir los contaminantes hasta los límites admisibles (Figura 15).

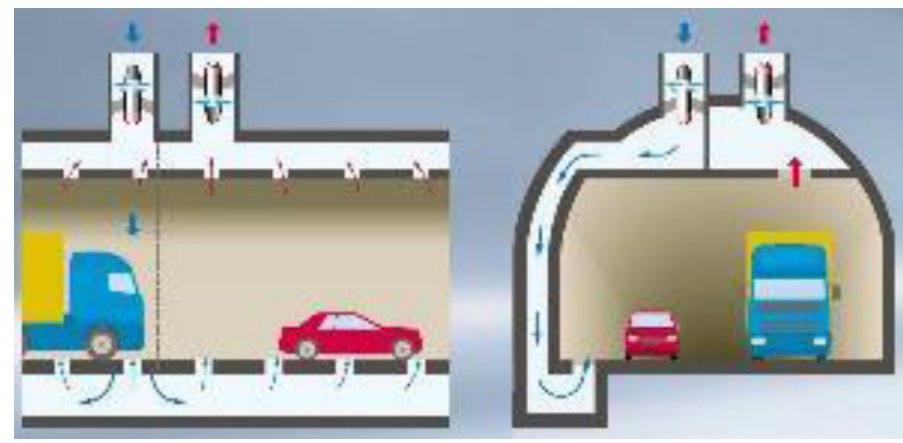

Figura 15: Ventilación transversal 


\section{Ventilación pseudo-transversal}

La ventilación pseudo-transversal es similar a la transversal pura salvo que se diseña de manera tal que el aire contaminado que se extrae es menor que el aire fresco insuflado, saliendo por las bocas la diferencia entre ambos. En caso de incendio, la extracción de humos con este sistema de ventilación será menor, en principio, que en la ventilación transversal pura.

\section{Ventilación por condiciones de confort}

La ventilación también es importante para mantener unas condiciones de confort mínimas en el interior de los túneles, y no solamente durante la construcción. Eso es más frecuente en túneles de metro y en sus estaciones, así como puede llegar a ser necesario en algunos túneles largos y con mucha cobertura. Por ejemplo, en ciudades en climas de veranos calurosos, la ventilación cumple también la función de refrigerar no solamente las estaciones, sino también los propios túneles. Dado que los trenes llevan equipos de climatización, el calor expulsado por éstos se va acumulando y calentando el túnel, transmitiéndose al revestimiento que no es capaz de evacuarlo ni absorberlo a lo largo del tiempo, lo que hace más difícil la operación y mantener unas condiciones de confort en las propias estaciones. La ventilación se encarga de conseguir este equilibrio térmico.

En algunas estaciones del metro de Buenos Aires en Argentina, en las líneas más antiguas, se utilizan ventiladores situados en los andenes a fin de mover el aire y tratar de rebajar la sensación de ahogo (los trenes están climatizados). Un sistema similar de ventilación activa se utiliza en el metro de Santiago de Chile, sin embargo, representan un alto gasto energético y no representa una solución efectiva (Bugueño, 2019). Sistemas de metro más modernos (y con mayores recursos), como es el metro de Doha en Catar, están totalmente climatizados, no solamente las estaciones, sino también el propio túnel

\section{Trampillas y exutorios}

El aire fresco suele insuflarse a través de aberturas (trampillas) situadas en la acera (a nivel prácticamente de la calzada). El aire contaminado (más caliente que el fresco) generalmente se extrae por la parte superior (es frecuente que sean trampillas ubicadas en el falso techo, donde igualmente se ubican los conductos de ventilación tanto aire fresco como del viciado). Los grandes exutorios para la extracción masiva de humos en caso de incendio se ubican en la parte alta de la sección (Figura 16).

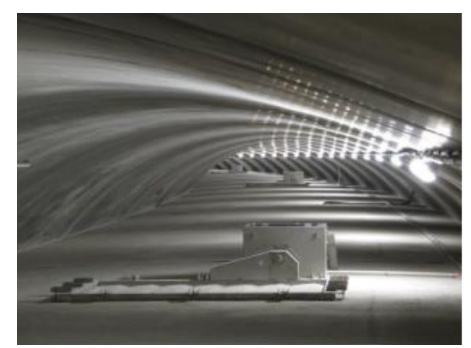

Figura 16: Exutorio de acero en un túnel, resistencia $400{ }^{\circ} \mathrm{C}$ durante $120 \mathrm{~min}$ (Warenzeichenverband Edelstahl Rostfrei/ Sirocco Luft- und Umwelttechnik, tunnel-online.info 2015)

\section{Ventilación versus condiciones atmos- féricas}

En caso de incendio, el sistema de ventilación se ha de diseñar para extraer los humos, por ejemplo, accionando el exutorio de extracción masiva de humos localizado más próximo al fuego, así como para garantizar que en las proximidades del fuego la corriente longitudinal de aire pueda ser controlada para poder confinar los humos. Este importante último aspecto deberá ser estudiado cuidadosamente pues las diferentes presiones barométricas entre las bocas y el efecto chimenea (más importantes en túneles largos, atravesando grandes macizos montañosos, con presiones barométricas muy diferentes entre una y otra boca, y con significativas diferentes temperaturas del aire dentro del túnel y en el exterior del mismo) puede dificultar muy seriamente el control del aire dentro del túnel, y por ello complicar el control de humos en caso de incendio (así como el control de contaminantes en funcionamiento ordinario del túnel). Ese aspecto debe ser considerado en el diseño de la ventilación

\section{Medidas en el túnel de Gotschna en Suiza}

Medidas realizadas entre diciembre del 2001 y octubre del 2002 en el túnel de Gotschna en Suiza mostraron que durante el $75 \%$ del año el aire del interior del túnel está más caliente que el del exterior, sucediendo lo contrario en el resto del año. Como consecuencia de ello se consideró como criterio de diseño la combinación de temperaturas en el exterior del túnel de $-11^{\circ} \mathrm{C}$ y en el interior de $+10^{\circ} \mathrm{C}$ (Figuras 17 y 18). 
El túnel fue inaugurado el 9 de diciembre de 2005. Posee una longitud de $4200 \mathrm{~m}$, es bidirecional, 1 carril por sentido. Tiene una sección útil al paso del tráfico de 46.8 $\mathrm{m}^{2}$, diámetro hidráulico de $6.7 \mathrm{~m}$, una inclinación media de $4.6 \%, 1155 \mathrm{msnm}$ de altitud y una diferencia de altitud entre portales de $200 \mathrm{~m}$. La ventilación es semitransversal con 2 estaciones de ventilación en portales con 2 ventiladores axiales en cada una (uno para insuflar aire y el otro para extraerlo), con conductos para ventilación en el falso techo (exutorios cada $70 \mathrm{~m}$ ). Para contrarrestar el efecto adverso por flotabilidad y poder garantizar el control de humos (para su extracción) en caso de incendio fueron necesarios instalar 24 jet-fans (de $22 \mathrm{~kW}$ cada uno) en el interior del túnel.

a)
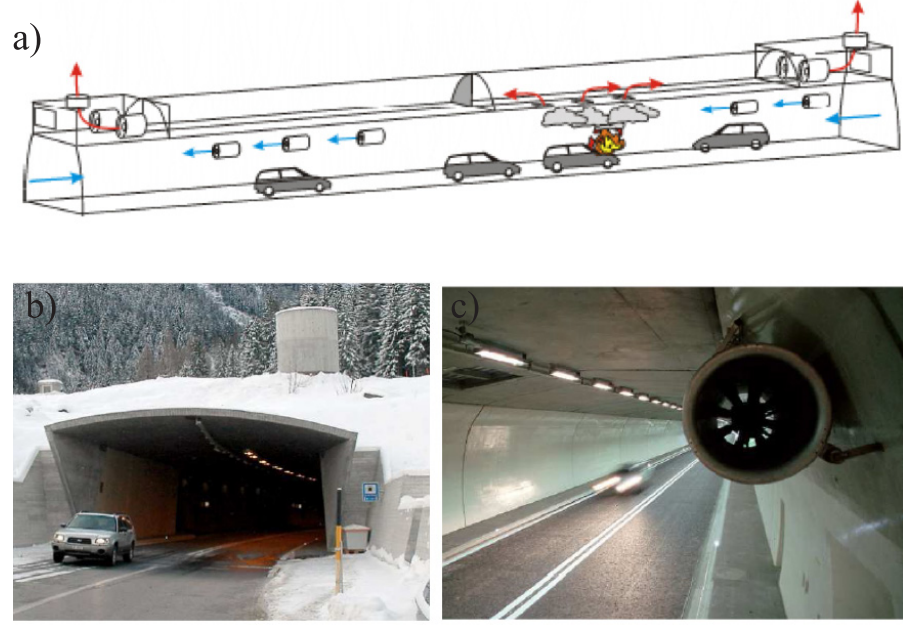

Figura 17:Túnel de Gotschna, A 28, by-pass de Klosters, Cantón Grisones, Suiza: a) esquema de la ventilación en caso de incendio, b) boca de entrada y pozo de extracción de humos y c) uno de los 24 jet-fans instalados en el túnel (hbi.ch)

Aunque no es frecuente, en algunos túneles profundos y largos la temperatura del macizo rocoso puede obligar a tomar medidas de refrigeración, no sólo durante la construcción, lo que es sabido, sino también durante la explotación (Andreae, 1948; Jaeger, 1972; Hacar, 1979). Los estudios de Rybach y Busslinger (2013) en el túnel suizo ferroviario de Base de San Gotardo (Gotthard Base Tunnel GBT) de $57 \mathrm{~km}$ de longitud, y cobertura máxima de $2450 \mathrm{~m}$, mostraron la correcta precisión de los complejos modelos de cálculo, pudiendo comparar las previsiones de dichos modelos con las temperaturas medidas durante la ejecución de los trabajos.

La aplicación de esos modelos al túnel austríaco también ferroviario de Koralm (forma parte del tramo de alta
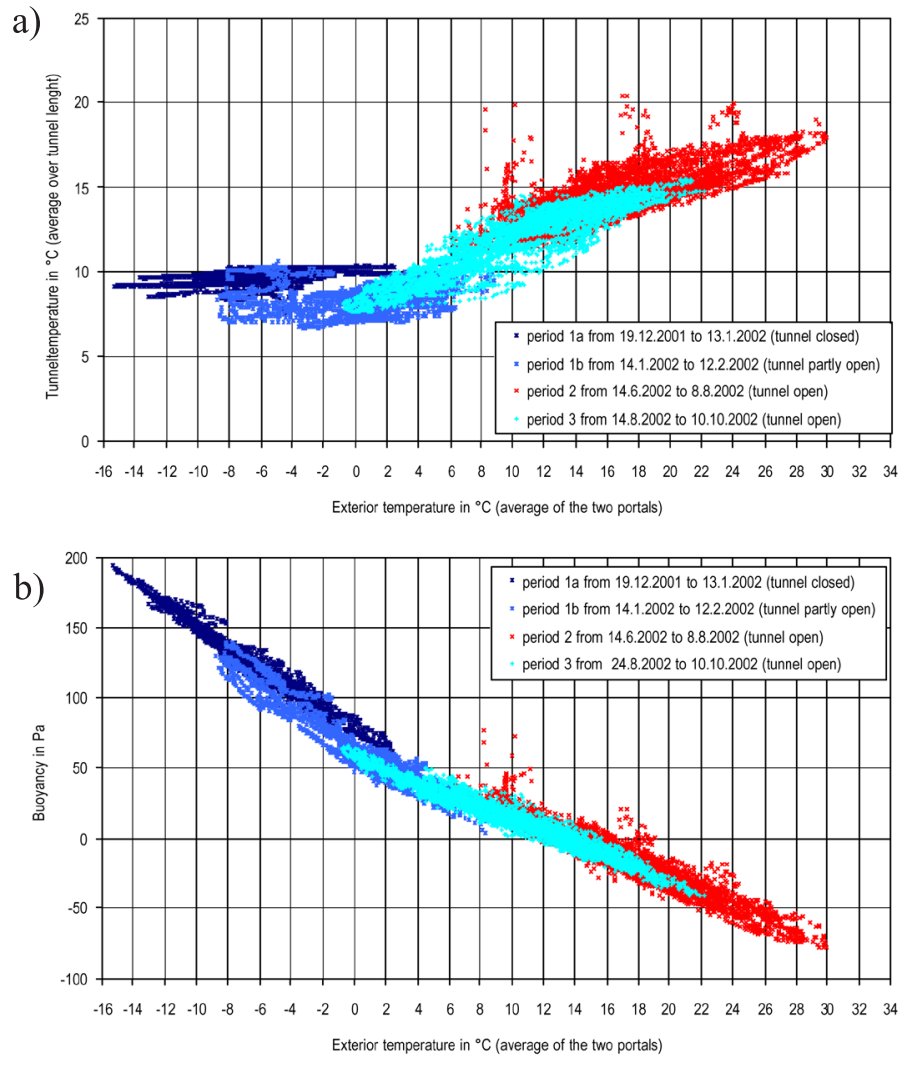

Figura 18: Túnel de Gotschna, mediciones de: a) temperatura promedio interior a lo largo del túnel versus temperatura promedio entre las dos bocas medidas en el exterior del túnel y b) flotabilidad (efecto chimenea) versus temperatura exterior del túnel (promedio entre las dos bocas) (Steinemann et al., 2004)

velocidad entre Graz y Klagenfurt, al sur de Austria; se prevé abrirlo al tráfico en el 2025), de $32.9 \mathrm{~km}$ de longitud, y cobertura máxima de $1200 \mathrm{~m}$, indican que durante la explotación hará falta refrigeración en aquellas galerías de interconexión entre tubos que contengan equipamientos, si bien en el resto se considera que con la ventilación prevista no es preciso proceder a dicha refrigeración (Fruhwirt et al., 2018).

\section{Medidas en el túnel de San Gotardo}

De $16.9 \mathrm{~km}$ de longitud, en su momento fue el túnel carretero más largo del mundo. Con tráfico bidireccional, la sección útil para el paso del tráfico es de $40.5 \mathrm{~m}^{2}$, diámetro hidráulico de $6 \mathrm{~m}$, calzada de $7.8 \mathrm{~m}$ (2 carriles) y aceras a ambos lados de $0.7 \mathrm{~m}$. Construido entre $1970 \mathrm{y}$ 1980, fue abierto al tráfico el 5 de septiembre de 1980. La inclinación media del túnel es de $0.4 \%$, donde la cota en el lado Göschenen es de 1080 msnm y en el lado Airolo de $1146 \mathrm{msnm}$, con una altitud media de $1120 \mathrm{msnm}$ 
(Lombardi y Haerter, 1972). El sistema de ventilación es transversal (Figura 19).

Se realizaron medidas en el túnel de San Gotardo en Suiza durante 1 año, comenzadas el 24 de julio de 2003. Realizadas 4 pasadas a $70 \mathrm{~km} / \mathrm{h}$ registrando las medidas de temperatura a lo largo del túnel, se obtiene una temperatura media en el túnel de $23.2{ }^{\circ} \mathrm{C}$ (se observan los descensos de las temperaturas en la vertical de los pozos de ventilación que aportan aire fresco al interior del túnel). La temperatura en el exterior lado Göschenen (boca norte) fue de $8^{\circ} \mathrm{C}$, en el lado Airolo (boca sur) fue de $12^{\circ} \mathrm{C}$ (Figura 20a). Las diferencias de presiones barométricas entre las bocas alcanzan el máximo de $3700 \mathrm{~Pa}$ durante $1 \mathrm{~h}$ entre el 22 y el 26 de diciembre de 2003 (Figura 20b).

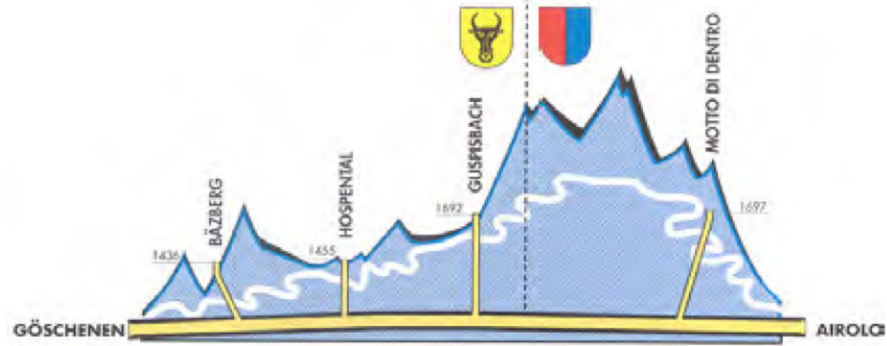

Figura 19: Sistema de ventilación en el túnel San Gotardo, autopista A2 Basilea-Chiasso (Bettelini et al., 2003)

a)

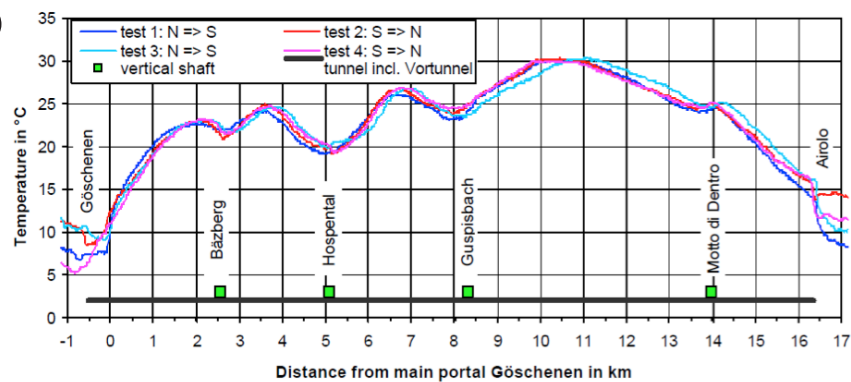

b)

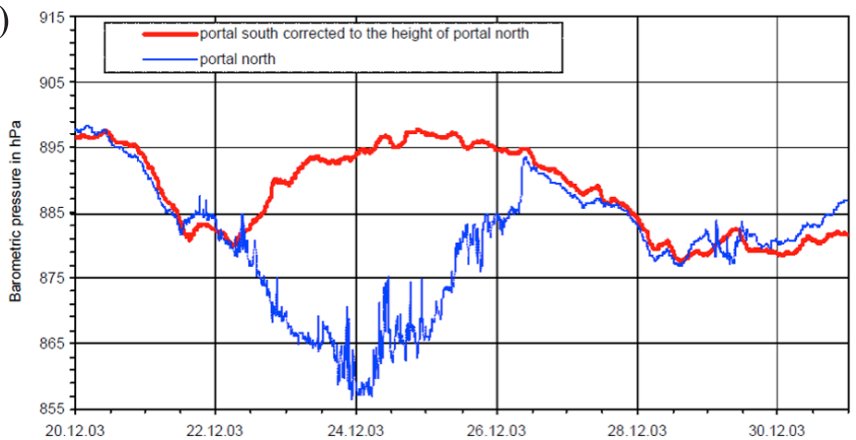

Figura 20: a) Distribución de la temperatura en el túnel carretero de San Gotardo el 4 de febrero 2004 y b) periodo con presiones barométricas extremas entre portales (Steinemann et al., 2004)

\section{Medidas en los túneles de Tauern, Gleinalm y Arlberg}

También son interesantes las medidas realizadas en los importantes túneles de Austria de Tauern, Gleinalm y Arlberg (Tabla 1).

Tabla 1: Diferencia de presiones barométricas entre portales (Sturm et al., 2012)

\begin{tabular}{|l|c|c|c|}
\hline \multirow{2}{*}{\multicolumn{1}{c|}{ Túnel }} & $\begin{array}{c}\text { Longitud, } \\
\mathrm{m}\end{array}$ & \multicolumn{2}{c|}{$\begin{array}{c}\text { Diferencia de presión } \\
\text { entre las bocas, Pa }\end{array}$} \\
\cline { 3 - 4 } & $\begin{array}{c}\text { Sentido } \\
\text { N-S o W-E }\end{array}$ & $\begin{array}{c}\text { Sentido } \\
\text { S-N o E-W }\end{array}$ \\
\hline $\begin{array}{l}\text { Tauern } \\
\text { (Autopista 10) }\end{array}$ & 6546 & 254 & 235 \\
\hline $\begin{array}{l}\text { Gleinalm } \\
\text { (Autopista A 9) }\end{array}$ & 8320 & 268 & 86 \\
\hline $\begin{array}{l}\text { Arlberg } \\
\text { (Autovía S 16) }\end{array}$ & 13972 & 206 & 209 \\
\hline
\end{tabular}

\section{Soluciones para controlar la corriente longitudinal en túneles existentes}

En túneles existentes los jet-fans necesarios instalar -reversibles- para controlar el aire del túnel en caso de incendio (para contener los humos mientras se realiza la extracción) puede obligar, o bien, a instalar un importante número de pequeños jet-fans a lo largo del túnel, o bien instalar menos jet-fans pero de mayor tamaño.

En esta última opción, para conseguir el espacio necesario dentro de la sección del túnel para ubicar los jet-fans habrá que intervenir en la obra civil, instalándolos por ejemplo en nichos, para lo que se deberá modificar el falso techo o los hastiales para dar cabida a esos jet-fans de mucho mayor tamaño (Beyer et al., 2016). En ambos casos se ha de verificar que la corriente de aire no afecte a los motoristas que puedan estar circulando por el túnel. En cualquier caso que se adopte, se deben hacer estudios en detalle para determinar la potencia que han de tener esos jet-fans, su ubicación en tanto la sección del túnel como a lo largo del mismo, la conveniencia de instalar deflectores para mejorar el coeficiente de instalación.

Las Figuras 21 y 22 muestran soluciones para el control de la corriente longitudinal de aire instalando jet-fans o toberas Saccardo como se muestra en la Figura 23. 


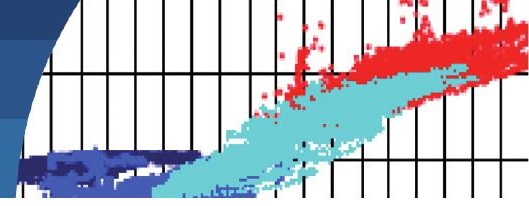

a)

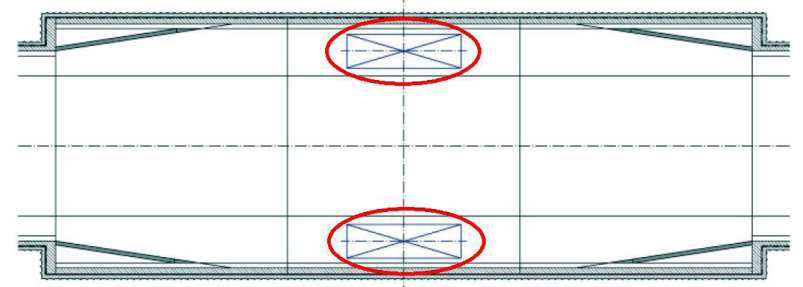

b)

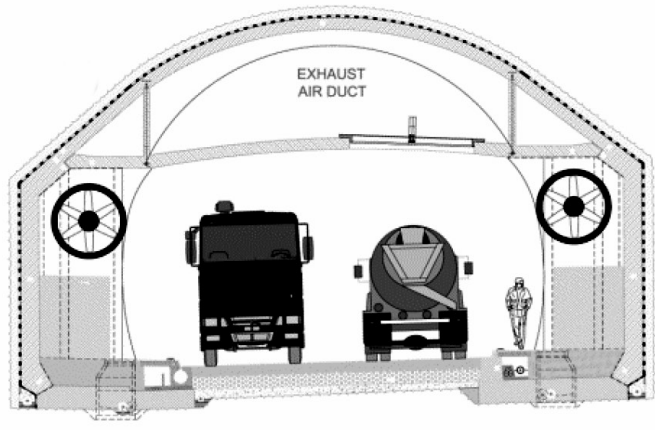

c)

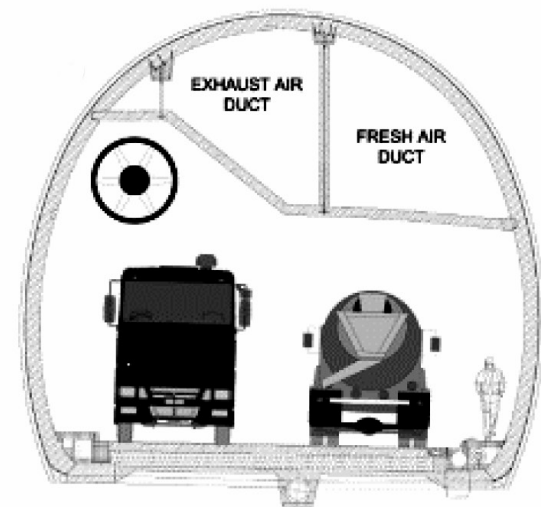

Figura 21: Instalación de jet-fans en túneles existentes para controlar la corriente de aire en el túnel: a) vista en planta, b) jetfans en hastiales y c) jet-fans en nicho practicado en el falso techo (Sturm et al., 2014).

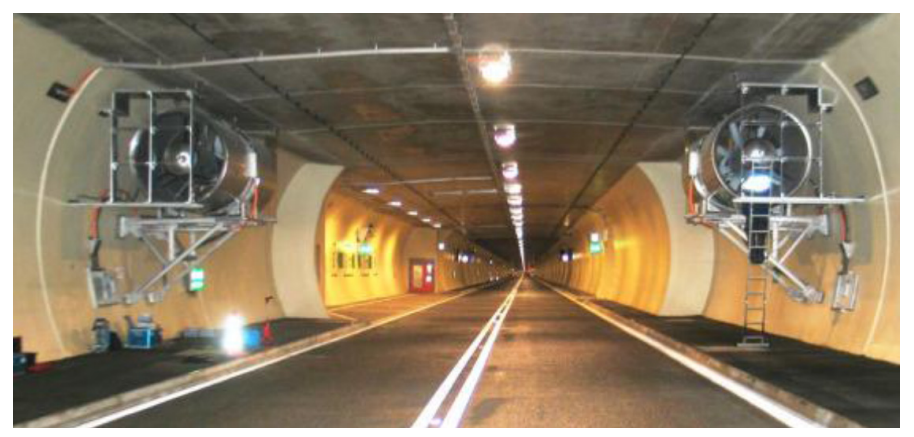

Figura 22: Túnel de Bosruck, Austria. Instalación de 8 grandes jet-fans de $2700 \mathrm{~N}$ cada uno en 4 nichos de ventilación en lugar de los 40 jet-fans que hubieran sido necesarios para cada tubo (Sturm et al., 2017)

Las toberas Saccardo (eyectores Saccardo o boquillas de impulsión, patente GB-189802026A, 25 de enero de 1898: Improved method and apparatus for ventilating tunnels) trabajan introduciendo un chorro de aire en el túnel a a)
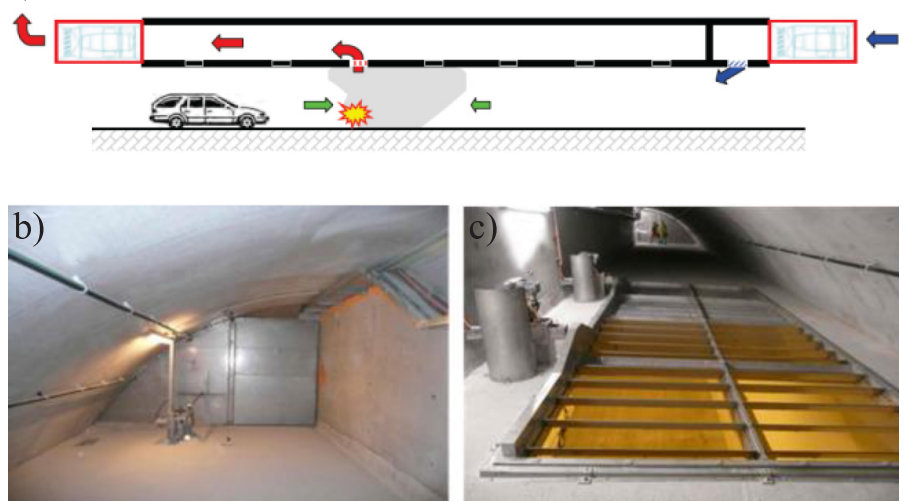

Figura 23: Túnel de Katschberg, Austria: a) instalación de toberas Saccardo en túneles existentes para controlar la corriente de aire en el túnel, b) muro de separación y c) inyección de aire fresco (Sturm et al., 2014, 2017).

alta velocidad, a unos de $30 \mathrm{~m} / \mathrm{s}$. Unas cámaras situadas normalmente en los portales alojan los ventiladores de impulsión del aire del exterior al túnel con un ángulo de $30^{\circ}$ o menor (Tarada y Brandt, 2009).

Este sistema con toberas Saccardo se puede considerar que es un tipo de ventilación longitudinal, ya que el principio de funcionamiento es similar al de la ventilación longitudinal con jet-fans, esto es, se inyecta un caudal de aire en la sección del túnel creando una corriente de aire longitudinal facilitando una dirección de la corriente de aire en el túnel predefinida. También puede ser producida por inyecciones puntuales de aire, por ejemplo, desde un pozo de ventilación,

Las Figuras 24 y 25 muestran esquemáticamente la construcción y ventilación de los túneles ferroviarios de Guadarrama (línea ferroviaria de Alta Velocidad Española AVE Madrid-Segovia-Valladolid) de una longitud de 28.4 $\mathrm{km}$. Formado por 2 tubos gemelos, uno para cada sentido de la circulación, el inicio de la construcción comenzó a finales del año 2002, y la puesta en servicio el 22 de diciembre de 2007. En estos túneles ferroviarios y en los de metro, el empleo de toberas Saccardo es mucho más frecuente que en los túneles carreteros.

Utilizando la ventilación principal y las toberas Saccardo se realizan simulaciones numéricas del sistema de ventilación con las siguientes hipótesis de partida (Zitrón, 2006):

- En uno de los tubos se produce un fuego de $50 \mathrm{MW}$ y por ello ha de garantizarse una velocidad crítica de $3.1 \mathrm{~m} / \mathrm{s}$. 
- En el tubo no siniestrado se ha de realizar la presurización del mismo, para ello se busca que haya 100 Pa más que en cualquier zona del tubo en el que se ha producido el fuego.

a)
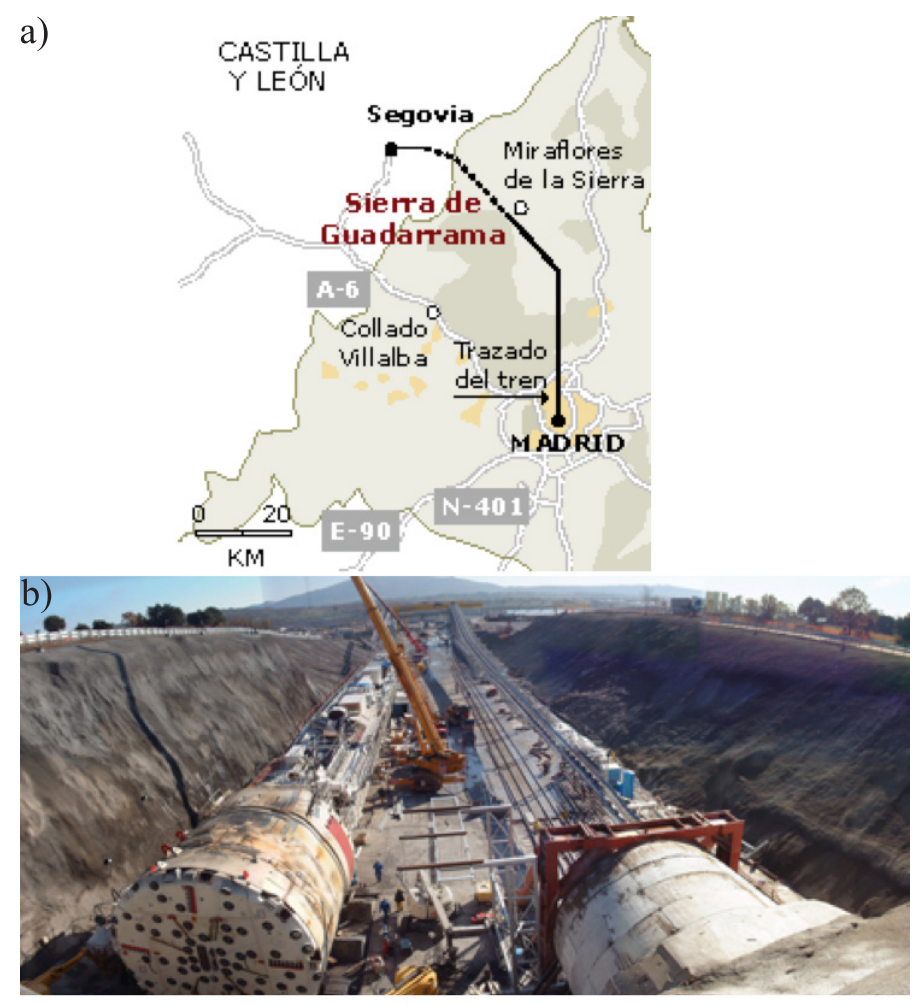

Figura 24: a) Ubicación de los túneles de Guadarrama, Comunidad de Madrid-Comunidad de Castilla y León, España y b) túneles en construcción-Bocas Sur (26 de noviembre 2002)

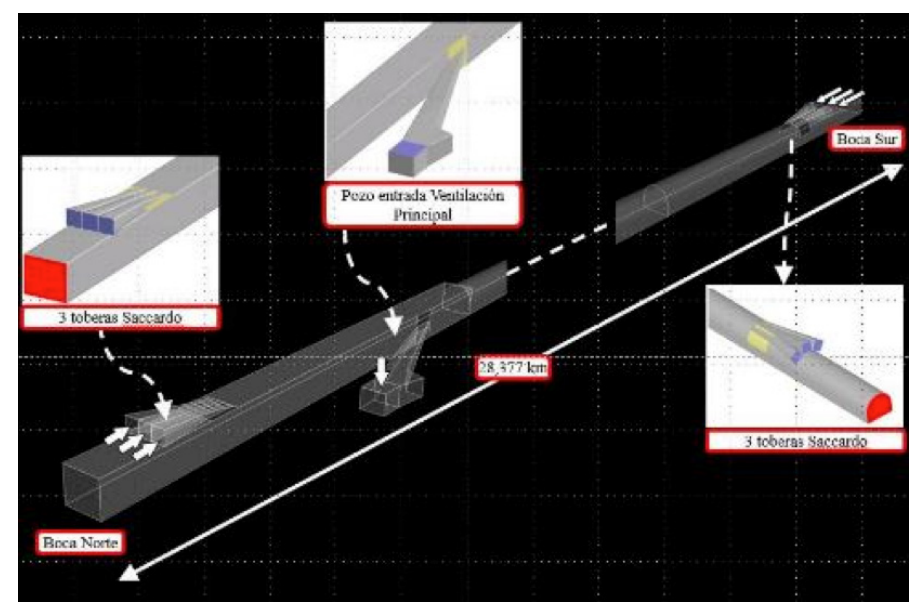

Figura 25: Esquema de la ventilación de los túneles de Guadarrama, Comunidad de Madrid-Comunidad de Castilla y León, España (Zitrón, 2006)

\section{Comentarios finales}

De aquellos túneles para peatones y carruajes con tracción animal que no precisaban ventilación, llegando a la tracción a vapor, y al motor de combustión, unido a túneles carreteros largos y con importante tráfico de vehículos ligeros, pesados y mercancías peligrosas, los sistemas de ventilación (y su relación con otros sistemas de seguridad como son las galerías de evacuación de emergencia) además de tener que mantener una calidad del aire dentro del túnel adecuada, han de dimensionarse para dar seguridad en caso de fuego. Los vehículos eléctricos supondrán otros nuevos criterios de dimensionamiento de esos sistemas de ventilación y de seguridad en los túneles.

\section{Referencias}

Alarcón, E. (2011). Técnicas de evacuación de humos y gases en túneles. Planes de autoprotección en túneles. Ministerio del Interior. España

Andreae, C. (1948). Les grands souterrains Transalpins. Leemann editeurs, Zürich, Suisse

Anónimo (1849). El triunfo de la ciencia. Una descripción de la gran flotación de uno de los tubos monstruo sobre el estrecho de Menai. Britannia Bridge. James Rees, Gran Bretaña (en inglés)

Asfinag Bmg (2014). A11 Karawanken Autobahn, Karawankentunnel. 2. Röhre. IL, Ingenieurbüro Laabmayr \& ZT GesmbH, Salzburg, Austria

Bendelius, A.G. (1982). Tunnel ventilation. In Tunnel Engineering Handbook. Kuesel, T.R. and Bickel, J.O. (eds.), Van Nostrand Reinhold, New York, USA

Bettelini, M., Neuenschwander, H., Henke, A., Gagliardi, M. and Steiner, W. (2003). The fire in the St Gotthard tunnel of October 24, 2001. International Symposium on Catastrophic Tunnel Fires, SP Swedish National Testing and Research Institute, H. Ingason (ed.), Borås, Sweden, 49-68

Beyer, M., Sturm, P.J., Saurwein, M. and Bacher, M. (2016). Evaluation of jet fan performance in tunnels. $8^{\text {th }}$ International Conference on Tunnel Safety and Ventilation, Graz, Austria

Brandt, R. and Cufer, A. (2006). Upgrading the Karavanken Tunnel according to the EU-Directive 2004/54/EC. 8th International Conference on Tunnel Construction and Underground Structures, International Tunnelling and Underground Space Association ITA. Ljubljana, Slovenia

Bugueño, E.O. (2019). Oasis urbano: una propuesta de acondicionamiento térmico para el metro de Santiago. Revista Hábitat Sustentable 9(2), 16-29 
Directiva 2004/54/CE. Requisitos mínimos de seguridad para túneles de la red europea de carreteras. Diario Oficial de la Unión Europea DOUE, 7 de junio 2004. Parlamento Europeo y Consejo de la Unión Europea

Fonseca García, J.M. (1987). Exposición: El Ingeniero y la Obra Subterránea. Colegio de Ingenieros de Caminos, Canales y Puertos. Madrid, España

Fruhwirt, D., Bacher, M., Sturm, P.J. and Steiner, H. (2018). Change in thermal conditions during construction and operation of a long railway tunnel. Taking the Koralmtunnel as an example. 9th International Conference on Tunnel Safety and Ventilation. New Developments in Tunnel Safety, Graz, Austria

González Crespo, J.L. y Hacar Rodríguez, F. (2015). Pajares: De barrera entre mundos a camino sin fronteras. Arts\&Press, Madrid, España

Gray, C.C. and Hagen, H.F. (1931). The eighth wonder: The Holland vehicular tunnel. Annual Report of the Board of Regents of the Smithsonian Institution, Washington, USA

Hacar, F. (1979). Temperatura en los túneles. Revista de Obras Públicas 3167, 217-223

Holland, C.M. (1921). Linking New York and New Jersey. The American City 24(3), 231-232

Jaeger, C. (1972). Rock mechanics and engineering (2.2.1 Predicting the temperature inside a deep tunnel). Cambridge University Press, UK

Jevenois, P. (1927). El túnel submarino del estrecho de Gibraltar. Estudio científico de su posibilidad. Capítulo II Ideas sobre los medios de unir dos continentes, y breve reseña de proyectos de túneles submarinos. Editorial Voluntad, Madrid, España

Legouëz, R. (1897). De l'emploi du bouclier dans la construction des souterrain. Librairie Polytechnique Baudry et Cie, Éditeurs, Paris, France

Lombardi, G. et Haerter, A. (1972). N2 Le tunnel routier du StGothard: Le projet du tunnel. Service Topographique Fédéral.

RVS 09.02.31 (2008). Guidelines and regulations for highway construction. Tunnels: tunnel equipment ventilation. Basic principles. Austrian Research Association for Roads, Rail and Transport, Vienna, Austria
Rybach, L. and Busslinger, A. (2013). Verification of rock temperature prediction along the Gotthard Base Tunnel. A prospect for coming tunnel projects. World Tunnel Congress WTC 2013, G. Anagnostou and H. Ehrbar (eds.), Geneva, Switzerland

Sandström, G.E. (1963). Tunnels. Holt, Rinehart and Winston. New York, USA

Steinemann, U., Zumsteg, F. and Wildi, P. (2004). Measurements of air flow, temperature differences and pressure differences in road tunnels. 2nd International Conference on Tunnel Safety and Ventilation. Graz, Austria, 220-226

Sturm, P.J., Beyer, M. and Rafiei, M. (2017). On the problem of ventilation control in case of a tunnel fire event. Case Studies in Fire Safety, Elsevier, vol. 7, 36-43

Sturm, P.J., Bacher, M. and Wierer, A. (2014). Strategies for fire ventilation. 6th International Symposium on Tunnel Safety and Security, Marseille, France

Sturm, P.J., Beyer, M., Bacher, M. and Schmölzer, G. (2012). The influence of pressure gradients on ventilation design. Special focus on upgrading long tunnels. 6th Symposium on Tunnel Safety and Ventilation, Graz, Austria

Tarada, F. and Brandt, R. (2009). Impulse ventilation for tunnels. A state of the art review. 13th International Symposium on Aerodynamics and Ventilation of Vehicle Tunnels. Brunswick, New Jersey, EEUU

The Engineer (1879). Severn tunnel. 24 October 1879

Yagües, N. (2011). Queensway: el primer túnel de carretera subterráneo bajo el río Mersey. Cimbra: Revista del Colegio de Ingenieros Técnicos de Obras Públicas 396, 36-43

Zitrón (2006). Estudio aerodinámico de la ventilación en el túnel ferroviario de alta velocidad (Guadarrama). Informe Versión 2.0. 